\title{
Rural-to-urban migration, kinship networks, and fertility among the Igbo in Nigeria
}

\author{
Daniel Jordan Smith \\ Department of Anthropology, Box 1921, 128 Hope Street, Brown University \\ Providence, Rhode Island 02912 U.S.A. \\ Tel: 1-401-863-7065, Fax: 1-401-863-7588 \\ Daniel_J_Smith@brown.edu
}

\begin{abstract}
Like many African rural-to-urban migrants, lgbo-speaking migrants to cities in Nigeria maintain close ties to their places of origin. 'Home people' constitute a vital core of most migrants' social networks. The institution of kinship enables migrants to negotiate Nigeria's clientelistic political economy. In this context, dichotomous distinctions between rural and urban can be inappropriate analytical concepts because kinship obligations and community ties that extend across rural and urban space create a continuous social field. This paper presents ethnographic data to suggest that fertility behavior in contemporary Igbo-speaking Nigeria cannot be understood without taking into account the ways in which rural and urban social and demographic regimes are mutually implicated and dialectically constituted (anthropological demography; migration; kinship; reproductive behavior; Nigeria!.
\end{abstract}

\section{Introduction}

Anthropological demography has contributed increasingly to the understanding of population processes and demographic behavior (Greenhalgh 1995; Kertzer and Fricke 1997; Johnson-Hanks 2007). Anthropological scholarship on population issues in subSaharan Africa has deepened and extended the analysis of a range of contemporary demographic issues, including fertility (Bledsoe 2002; Smith 2004), marriage (Johnson-Hanks 2006), migration (Trager 200I; Whitehouse 2007), and the AIDS epidemic (Setel 1999). This paper combines two intersecting issues in the study of African population processes: migration and fertility. It uses ethnographic data to show how ruralto-urban migration and reproductive behavior are deeply intertwined.
A growing literature addresses the relationship between social networks and fertility processes. Some demographers have begun to explore the influence of social networks fertility preferences, adoption of modern methods of contraception, and actual changes in fertility outcomes (e.g., Entwisle et al. 1996; Rutenberg and Watkins 1997; Kohler et al. 200I; Madhavan et al. 2003). While most demographic analyses of social networks have tended to focus on the role of networks in facilitating reproductive innovation and contraceptive diffusion, the data here show how the importance of kinship networks in Nigeria creates rational incentives for relatively high fertility, even among a group of modernized and urbanized people who also experience growing constraints and 
changing aspirations that would appear to propel fertility decline. Based primarily on ethnographic data, I argue that for the lgbo people of southeastern Nigeria, social networks built upon the institutions and idioms of kinship mediate access to modern political, economic, and social resources and opportunities (Berry 1989; Bayart 1993; Chabal and Daloz 1999). Because the social reproduction of these kinship networks is essential for survival and success in the modern Nigerian world, and because marriage and childbearing are fundamental to the creation and reproduction of kinship ties, Igbos experience tremendous social pressure and perceive important personal incentives for continued high fertility, even as they also face competing constraints.

The reasons for looking at the impact of social networks on reproductive behavior across rural-urban boundaries are three. First, given that urban migration and assimilation to urban life are conventionally associated with fertility decline (Brockerhoff and Yang 1994), examples of how social networks that reach across rural and urban communities may act to perpetuate relatively high fertility can serve as an important corrective to looking at social networks simply for their contributions to innovation. Second, a focus on kinship networks helps emphasize the importance of thinking about social networks as institutions (Mitchell 1973; Faist and Ozveren 2004); that is, as corporate groups and not just as ego-centered networks of communication and interaction. The literature on social networks in demography has been, arguably, overly enamored with conversational networks, a model that pre- serves through the back door the very thing network analysis purports to be addressing: the uncritical acceptance of the notion that fertility decisions are fundamentally 'individual'. Finally, in Nigeria, as in much of sub-Saharan Africa, the fluid nature of rural-to-urban migration and the strength of ties to place of origin mean that the very categories rural and urban may not be appropriate for delineating the social field of interest. That is, rural and urban reproductive regimes can be - and arguable often are - mutually constituted across rural-urban boundaries.

\section{Literature review and theoretical framework}

With an estimated population of 160 million people, Nigeria is the most populous country in Africa. The Igbospeaking people of the southeastern region are one of more than 300 ethnic groups that constitute Nigeria's diverse cultural landscape. Along with the Hausa of the north and the Yoruba of the southwest, the lgbo are one of the three largest groups, by most estimates numbering more than 20 million. In many ways, the lgbo case is ideal for exploring the apparent contradiction of persistent high fertility in areas of subSaharan Africa that are relatively modernized. The total fertility rate in the lgbo region is still more than four per woman (4.I) (National Population Commission (NPC) [Nigeria] and ORC Macro 2004: 53). The region is one of the most densely populated places on the continent. Population pressure is a palpable issue in the everyday lives of lgbo people, as land-holdings become increasingly fragmented and families are not able to live by farming alone. 
Indeed, few lgbo households subsist exclusively through agricultural production. Most Igbo families survive by relying on a combination of economic activities, many of which involve migration.

Rural-to-urban migration has burgeoned in Nigeria over the past two to three decades, and Igbos constitute a large proportion of this migrant population. Every city and town across Nigeria has significant lgbo communities known for their domination of specific sectors of the marketplace (e.g., Silverstein 1984). In the village where I conducted my dissertation fieldwork from 199597, about three-quarters of adult men and women had lived at least one year of their lives in a major city and over half of the village residents had at least one relative living in Lagos, Nigeria's biggest city. In subsequent years, high levels of rural-to-urban migration have continued. Many lgbos spend a significant period of their lives in the city and there is considerable movement back and forth between the village and the city (Uchendu 1965; Chukwuezi 200I). In addition, even among migrants who settle relatively permanently in the city, ties to 'home' and 'home people' remain powerful and important (Gugler 2002).

Even prior to the current period of tremendous migration, the Igbo were renowned for their receptivity to change (Ottenberg 1959). During the colonial period, they quickly accepted Christianity and formal education. In contemporary southeastern Nigeria one cannot help but be struck by lgbos' modern aspirations - for money, education, opportunities for migration, consumer commodities and so on. One might expect that they would be a vanguard in Nigeria's and Africa's fertility transition. Yet Igbo people continue to value relatively large numbers of children. Among 235 ever-married women I surveyed in the village community where I conducted my research, the women reported an average of 5.46 live births (see below for a brief description of the research methods). Among younger people, the idea of planning a family has taken hold. But in southeastern Nigeria a planned family means having four or five children.

\section{Data, methods and study setting}

The study site for the research reported here is Ubakala, in Abia State in Igbo-speaking southeastern Nigeria. In addition to many years of participant observation, I conducted a household survey in one village, interviewing all ever-married women of reproductive age (15-49) and all men with wives of reproductive age. The total sample was 390 , including 153 husband and wife pairs. As part of my research, I also conducted sample surveys of university students $(n=406)$ and secondary school students $(n=775)$. When asked about their preferred number of children, secondary school students reported wanting a mean of 4.3 children and university students reported wanting a mean of 4 .I children. While these preferences are not reliable predictors of actual fertility, they give some indication of the continued value of relatively high fertility, even among the region's youngest, most educated, and most 'progressive' population.

Ubakala has a population of approximately 25,000 people in II villages 
spread across roughly 24 square miles. While still largely rural in character, the community bears the influence of being close to the town of Umuahia. The services of the state and commodities of the wider Nigerian economy are more readily available in Ubakala than in many more rural Igbo communities. ' Apumiri, the commercial and service center of the community, has a permanent market with several dozen small stall-like shops that sell most every necessity (and many luxuries) that people might need or desire. Local taxis and mini-buses regularly the ply the old road from Ubakala to Umuahia, and public and private vehicles constantly traverse the newer expressway, easily linking Ubakala with the rest of Nigeria.

Paramount among the principles that organize social life in Ubakala is kinship, and specifically the importance of lineal descent as the basis for individual and group identity. Like most Igbo communities, the people of Ubakala are patrilineal. ${ }^{2}$ Because most of the II villages in Ubakala trace their descent from a common ancestor, people especially men - share a general feeling of kinship with other natives of the community. This sense of kinship is expressed and recognized more or less strongly depending upon context. When at home in the community, cleavages - along the lines of village, hamlet, or lineage, for example - tend to be more pronounced. Away from Ubakala, when two natives meet in Lagos, for example, the sense of kinship is very strong, even if they are not closely related.

People use ideas of lineal descent and kinship to create and maintain relationships of duty and obligation that structure morality and behavior in powerful ways. In the village setting, children grow up with a wide range of classificatory mothers, fathers, sisters, and brothers. Individuals address all sorts of aunts, uncles, and cousins as mother (nne), father (nna) and brother/ sister (nwanne). Throughout the life course, individuals benefit from the help of their lineage mates. Similarly, every person is expected to assist members of his/her patrilineage (umunna At some points in the life cycle, such as at marriage ceremonies and burials, these expectations and obligations are codified through specific customs. People know exactly how much money or which commodities and symbolic offerings they must provide. More often, the expectations are more generalized, but individuals regularly feel pressure to help their people. These obligations extend beyond the patrilineage to include one's mother's people (umunne), one's in-laws (ndiogo), and a range of other allies and supporters created by ties of residence and association.

As alluded to earlier, one of the most profound and significant aspects of Igbo social organization is the degree to which lgbo communities extend and reproduce local social institutions and patterns across vast geographical and cultural space. In Ubakala, a huge proportion of 'sons' migrate to, and live in, Nigeria's many cities and towns. In addition, many of Ubakala's 'daughters' have also migrated with their husbands, not only to their husbands' natal communities, as was traditional, but to the far away places they and their husbands work and trade. In Lagos, there are easily a few thousand Ubakala natives. In 
other big cities like Kano, Kaduna, and Port Harcourt there are hundreds. Most Igbos who migrate retain close ties to their relatives and home communities. These migrants and their relatives 'at home' move back and forth between the village and the city. But perhaps more important, they literally reproduce many of the social structures from home in the city.

Thus, in each city across Nigeria migrants from Ubakala maintain a branch of the Ubakala Improvement Union (the formal name of the community development union), and in bigger cities each of the II villages of Ubakala has a branch of its own development union. In addition, the members of a lineage organize and hold regular family meetings, and the branches of lineages in the bigger cities are formally recognized at home. The reproduction of these social structural forms provides a sense of community and continuity, but it also extends the obligations of kinship across the Nigerian political and economic landscape. A native of Ubakala in Lagos will seek the help of kinsmen just as easily as he/she would at home perhaps more easily because the physical and cultural distance from home actually serves to reduce the social distance that might separate individuals in the village. The importance of 'having people' in Nigeria only makes full sense after understanding the way in which kinship and communities extend far beyond village boundaries. People manipulate and rely on these networks of kinship, affinity, and community to achieve their goals in the wider Nigerian society.

During fieldwork spanning almost two decades, I have studied ethno- graphically the social networks in which the lives of my informants were enmeshed. As such, I interviewed and interacted with the extended families, affines, neighbors, business associates, and friends of the families I studied. Pursuing these ties took me to nearby villages and towns, to far away cities like Lagos and Kano, and even across international borders (theoretically) when I talked to relatives who came home from abroad. Following these networks contributed to producing four important conclusions: I) that fertility 'decisions' in Igboland cannot be understood as simply individual or even dyadic, because a much wider spectrum of voices and interests have a say and must be considered in reproducing families; 2 ) that it is precisely by 'having people' - especially kinspeople - that the lgbo are able to get access to modern resources and opportunities; 3 ) that kinship networks must be understood not only as ego-centered networks of communication and interaction, but also as institutions - corporate groups with moral economies that shape and constrain the context of individual action; and 4) that urban migrants remain closely connected to their rural kin and communities to such an extent that their fertility decisions are influenced by and must be understood in the context of these ties.

The significance of incorporating this more social perspective is all the more striking in the lgbo context, given that Igbos have a reputation in Nigeria (and in the scholarly literature) for being entrepreneurial, individualistic, and economically competitive. The enduring importance of kinship and the collective social influences on fertility 
decisions are not posed here as an alternative view of lgbo culture, but rather to emphasize the importance of these features of social life even among a group where countervailing tendencies and pressures are powerful. While it is important to acknowledge that fertility is influenced by many factors, such that one sees significant variation between ethnic groups, regions, and between rural and urban areas in Nigeria and elsewhere in Africa, the striking finding emphasized here is the continued influence of kinship on the moral economy of fertility decisionmaking.

\section{Results}

Wealth in people: an organizing principle of social life

The structure of Igbo migrants' social life in the city cannot be understood without reference to the importance of home and home people. Igbos use the phrase 'home people' in English and in lgbo (ndiulo). Its meaning changes according to context. When in Lagos, Nigeria's commercial capital, home people can mean anyone from the same Igbo-speaking region, or more likely, the same local government area. More often, 'home people' refers to those originating from the same community or the same village. But across all contexts, one's kinspeople are always home people.

Throughout Africa, the enduring identification with one's ancestral village is widely prevalent (Geschiere and Gugler 1998). It characterizes an African construction of identity in the midst of the tremendous changes wrought by increasing modernization and urbanization. Throughout Nigeria, people of many ethnic groups retain ties to their villages and often build homes in their ancestral communities. Among Igbo people this identification with and continual returning home has been intensified by the experience of the Biafran War. From 1967-70, following bloody reprisals against Igbos living throughout Nigeria in the wake of a military coup, the people of southeastern Nigeria (mostly lgbo-speakers) sought to secede from Nigeria and create their own state, called Biafra (Kirk-Greene 197I; Post and Vickers 1973). In the aftermath of Biafra, during which up to a million lgbos were killed or starved to death, Igbo people lost property, buildings, and land, as laws about 'abandoned property' were used (at least in lgbo interpretations) to steal lgbo property outside Igboland. Today in Igboland, it is considered imperative to build one's first home in the village and foolish to build outside Igboland before building at home. Igbos often allude to Biafra and say they would not make the same mistakes again - meaning that they would not completely invest their livelihoods elsewhere because only home was truly safe. Though the importance of having people is not unique to the lgbo, the historical legacy of Biafra has made lgbo people acutely aware of who they can rely on in a world where success and survival depend upon having reliable, kinshipbased social networks of obligation and alliance.

Networks of home people, especially kinspeople, provide access to the opportunities and resources of the state and the Nigerian economy. The importance of these networks helps explain the continued value of high fertility, 
even as Igbo society is modernizing dramatically. The argument is that in Nigeria's political economy lgbos rely on social networks of kinship to obtain the opportunities, resources, and benefits associated with being modern. The notion that Africans depend on social networks to achieve wealth and status is not new, but the importance of kinship, and the place of fertility in social not just biological - reproduction, has important implications for understanding fertility in modern African settings.

Africanist scholars have long noted that an individual's status and security depends greatly on his ability to control dependents (Guyer 1993). As d'Azevedo (1962) explained about the Gola in Liberia, in Nigeria every adult is a patron to lesser people and a client to a more powerful person. Scholars such as Berry (1985) have highlighted the overlapping nature of the reciprocal obligations of kinship and the dynamics of patron-clientism. In my own research, it became clear that lgbos gain access to the resources of the state and the wider economy through social networks of reciprocity and obligation that have their roots in the family, the lineage, and the local community (Smith 200I).

The following cases from my fieldwork document the importance of having people for succeeding in contemporary Nigerian society. One case is about educating a child and the other is about the influence of home people on migrants' reproductive lives. Each illustrates the importance of kinship networks in migrants' social lives in ways that demonstrate both the institutional nature of such networks and their potential to reinforce the value of rela- tively high fertility among rural-tourban migrants.

Kinship networks and access to education

Education is both a marker of modernization in the minds of lgbo people and one of the most recurrent variables used by demographers to explain fertility declines. In demographic models of fertility transition, increasing levels of formal education are linked with decreasing fertility preferences via multiple pathways. On the one hand, attaining higher levels of education is perceived as costing parents more, part of a larger reversal in the direction of wealth flows in the family (Caldwell 1982). The large investments required to educate children, this model argues, discourage parents from having so many children. On the other hand, the impact of education itself is believed to increase the desire and capacity for family planning. In general, education is seen as contributing to the loosening of collective customary social controls and the flourishing of individual rationality. In particular, the education of women is seen as empowering them to take control of their reproductive lives. It is assumed - sometimes mistakenly - that 'rational' and 'educated' women will naturally want to have fewer children.

In Igbo-speaking Nigeria nearly all children go to primary school, and at least half start, though many do not finish, secondary school. Parents routinely complain about the high costs of 'training children', even as they do all that they can to further their children's education. But the burden of educating children as an incentive to reduce fertility is partly offset because the costs of education are widely shared. Parents 
rely heavily on the support of their kin. Relatives commonly contribute directly to the payment of school fees, offer a promising child free boarding near an urban school, or help a child's parents in other ways that free up resources for education. Wealth flows in horizontal and diagonal directions between all manner of lgbo kin, vastly complicating a model in which the costs of educating children are borne by the biological parents.

Perhaps more important, people's actual experience with access to education in Nigeria reinforces a model of how the world works which says: 'a person needs connections, especially family connections, to succeed'. The reality of how the world works in Nigeria changes the equation necessary to understand the context of people's fertility preferences. High fertility remains rational even in the pursuit of the most modern of goals. The following account of one young girl's route to secondary school is typical of how lgbos must negotiate and manage their networks of social relationship - especially networks of kinship - in order to access opportunities for modern education.

\section{Ethnographic case I}

Ike and Chinyere are lgbos living in Lagos. Ike struggles to make a small photocopying business profitable, while Chinyere has a steady but low-paying clerical job at a bank. They have been married more than 12 years and have four children.

When their eldest daughter, Ihunanya, completed primary school, lke and Chinyere had aspirations that she would be admitted to a selective federal government secondary school. Ihunanya was an excellent student, regularly finishing first or second in her class of forty. Ihunanya's parents wanted a particular federal school close to Ike's village community because it had a good reputation and Ike's relatives could assist in looking out for their daughter.

Ihunanya scored well on her secondary school admissions test, but not well enough to gain entrance to the federal school her parents wanted. Instead of the profound disappointment I had expected, Ike and Chinyere were upbeat. Since I had last seen them, Chinyere found out that her sister had a friend in the Federal Ministry of Education in Abuja. The woman in the Federal Ministry said that she would try to get lhunanya admitted through the Minister's 'discretionary list'. In the end, Ike and Chinyere had to 'dash' 3 the woman in the ministry some money for securing Ihunanya a place.

To understand Ihunanya's admission as based on a bribe would be a mistake, though clearly the 'dash' was a required part of the process. In fact, Ihunanya's admission was only possible because of Chinyere's sister's connection. The money involved actually represented a social distance in the connection. The woman in the ministry surely would have refused any dash to help her own sister's daughter, as opposed to her friend's sister's daughter. A complete stranger offering money to get on the Minister's list would likely have been rejected outright.

People are generally careful to circumvent state/bureaucratic rules only among those they know and trust, partly out of fear that rules can be used against them. But more significantly, instances of so-called corruption are far 
more likely when they are undertaken as the fulfillment of expectations and obligations to one's network of social relations - especially kinship and affinal relations. To accept money from a stranger to facilitate admission of a child who is not qualified based on her exam result is wrong: the rules of the state apply in such an impersonal case. To help your relation get admission when her scores were below the cut-off is expected and morally justified: the rules of kinship, community and reciprocity apply when the stakes are personal.

The story of Ihunanya's secondary school education is typical of parents' experiences. Igbos routinely rely on their kinship networks to facilitate educational goals. While many kin will contribute to a relative's education, such help comes with the expectation that when the person becomes successful he/she will not forget his/her benefactors. Of course help for or from one's kin often comes with ambivalence. Discourses of complaint about sons (and daughters) who do not 'remember' their kin are common. Talk about the burdens of what many youths call 'the African extended family system' is ubiquitous. But so too is the conclusion that 'we cannot avoid it, it is our culture'.

The widespread acceptance of formal education as a key credential in contemporary Nigeria has created for parents' costs and burdens that seem to fit with conventional demographic models of fertility transition. But in Nigeria, access to education depends fundamentally on one's social connections, and once access is secured, the burdens are widely shared among one's kinship networks in a system of obligation and reciprocity. While there are certainly strains on the system as some people feel left out or left behind, by and large the rise of education as a marker of modernization has solidified rather than eroded Igbo notions that you can only make it in the world by having people.

Corporate decisions: the long reach of home people

The second case study describes the influence of the extended family and place of origin on a migrant couple's reproductive decisions. While the evidence here is in the form of a single anecdote, it represents a wide range of similar stories I heard from Igbo migrants about the long reach of home people.

\section{Ethnographic case 2}

Kalu and Ngozi Eze reside in Lagos. They have lived there since before they married - almost fifteen years. Kalu sells motor vehicle spare parts in one of Lagos's vast sprawling markets. Ngozi works as a receptionist in the Federal Ministry of Works. Kalu was thirty-six, Ngozi thirty-two. They had three children, two sons and a daughter, ranging in age from II to five. Both Kalu and Ngozi hail from Ubakala, though from different villages. They met in Lagos through mutual friends. When they decided to marry, Kalu went home to initiate marriage negotiations with Ngozi's people. They completed the traditional igba nkwo ceremony about twelve years ago. Both are Methodist, and though they (especially Ngozi) would like to do a church wedding, they have never been able to afford it.

Kalu and Ngozi had a modern courtship. They saw themselves as in love' when they decided to marry. But 
their marriage, by both their accounts, has settled into a more pragmatic arrangement. Nonetheless, their marriage is fairly solidly companionate. They share one household budget, sleep together in one room every night, and discuss many family decisions jointly - especially regarding their children.

Ngozi had used an IUD for about four years. At first Kalu objected vehemently, saying that it was a sign of promiscuity - and that they were not finished having children. But Ngozi prevailed, mostly because Kalu agreed that they could not afford to have more kids yet - especially since Kalu's youngest brother was living with them in Lagos and Kalu was sponsoring him in secondary school.

Kalu and Ngozi go home to the village several times a year - sometimes together, sometimes individually. They remain closely tied to their natal communities. In addition to their regular visits home, they also receive many guests from home in their flat. Besides the movement back and forth between Lagos and Ubakala, there is a substantial community of home people in Lagos. They regularly get together - formally to take decisions about Lagos 'sons" contributions to community projects and life course rituals at home, informally to exchange news and gossip and utilize each other as messengers and resources.

Even in Lagos, Kalu and Ngozi remain subject to the gaze of their community. Among the aspects of their lives most surveilled is their fertility. Back home some of their relatives were concerned that there have been no children since the third, some five years before. Those concerns filtered back and forth between Lagos and Ubakala, and were sometimes voiced to Kalu and Ngozi by a subtle reference or even a bold question. Eventually 'the village' came to their door in the form of Kalu's mother. Kalu said:

One evening my mother arrived from the village unexpectedly. We were afraid that something bad had happened at home that someone had died. But my mother assured us there was no emergency at home. The next morning she revealed that 'the problem' which brought her to Lagos was here. When I said I didn't know what she meant, she said she and others were troubled that nothing had happened for five years. She had come to recommend we come home to visit a diviner. When I told her we were intentionally not having children and that Ngozi was using an IUD my mother was shocked. She condemned the practice and blamed Ngozi. How could we stop after only three kids, she asked? What was Ngozi after?

Ngozi was troubled by her mother-inlaw's accusations - even though they were only voiced to her by insinuation. She lamented the long reach of the extended family:

In our culture your marriage and your children are not simply your business. They are the business of the whole extended family and the whole village. Don't you see how my motherin-law came all the way here to complain about me? My husband has not said so, but I know he 
will soon demand another child.

When I asked whether she wanted another, she said she was not sure.

About 15 months after her motherin-law's visit Ngozi gave birth to the couple's fourth child. It would be a mistake to interpret the impact of Kalu's mother's visit simply to the pressure she applied as an individual. Rather, her critical comments and her wish that her son had more children must be understood as standing for the shared expectations of a moral economy rooted in kinship, a moral economy that remains powerful precisely because Nigeria's political economy continues to privilege patron-client ties. Kalu's mother's visit personified the collective expectations of the corporate kinship group. It would have been relatively easy to resist pressure from Kalu's mother if she acted only for herself. Rather than seeing Kalu's mother as one node in Kalu and Ngozi's ego-centered social networks, it is important to see her as representing a corporate group.

\section{Discussion}

For anthropological demography, the study of social networks provides both methodological and theoretical benefits. First, there is a natural relationship between doing ethnography (enmeshing oneself in everyday life) and studying social networks (Johnson 1994:132-4). Second, theoretically, the study of networks moves the focus of inquiry away from the rigidity of structural-functionalism and towards an understanding of how actual social relationships affect behavior (Hammel 1990; Mitchell 1973). Nancy Howell summarizes the benefits of network approaches succinctly:
Network - as compared with categorical - models have clear explanatory advantages in that they incorporate individual perceptions of social structure into larger concepts that subsume these same individual perspectives. Network models have the advantage, on the one hand, of corresponding to, and resonating with, important concepts in sociology such as roles, statuses, and group boundaries, and on the other, of being consistent with dynamic, processual views of social structure as it is formed, maintained, and transformed over time (Howell 1988:62).

But despite its potential usefulness, and the clear advantages over structuralfunctional approaches in anthropology and individualist conceptions of decision-making in demography, the actual practices of network analysis in anthropology and in demography have taken trajectories that have led to important omissions. This paper has attempted to redress two of those omissions, one in anthropology and one in demography.

In anthropology, the study of social networks has mostly been the province of urban anthropology (Mitchell 1969, 1974; Wolfe 1978; Zhang 200I). The rejection of structural-functionalism (which focused heavily on kinship) led to a dearth of work on social networks generated by kinship. As Johnson notes, ironically:

... it was the very people who contributed to making the study of social networks a legitimate enterprise in anthropology (i.e., social anthropologists studying 
more complex urban societies) that rejected the importance of more traditional constraints on behavior such as kinship (Johnson 1994:128).

Though Clyde Mitchell, one of the founding practitioners of social network analysis in anthropology, warned long ago that '...the opposition of networks and corporate groups (or institutions) must be a false dichotomy...' (1973:34), little anthropological work on social networks has focused on kinship.

In demography, and particularly in the study of fertility processes, practitioners of social network approaches try to take into account the influences of community and social relationships on fertility preferences, contraceptive choice, and reproductive outcomes. But the conception of what social networks are and how they impact human behavior has been too narrow. Almost all the demographic studies of social networks as they relate to fertility processes have been studies of conversational networks (e.g. Entwisle et al. 1996; Rutenberg and Watkins 1997; Valente et al. 1997; Watkins and Danzi 1995). This focus on conversational networks, while important, neglects the institutional dimensions of social networks. As Mitchell (1973) pointed out and others have more recently reemphasized (Emirbayer and Goodwin 1994), adequate accounts of social networks must acknowledge and explain the way in which 'social structure, culture, and human agency presuppose one and other' (Emirbayer and Johnson 1994:1413). In other words, social networks are not simply the lines of verbal communication that connect individu- als, they are simultaneously constitutive of the social institutions that shape and constrain them.

By focusing inordinately on conversational networks, network approaches to fertility-related behavior are reproducing the very notion that they purport to be rejecting - the assumption that atomistic individual choice is fundamental to reproductive behavior. Social networks, when conceived of principally as conversational networks, are theorized primarily as pathways for the diffusion of information - albeit information that sometimes implies the shifting of community norms. But this conception of social networks still privileges, tacitly, the Western ideal of the individual decision-maker, with all its assumptions about utility maximization and the nature of rationality. My argument, from ethnographic evidence in Nigeria, is that the role of social networks in structuring fertility regimes and fertility decisions is much more complex - with individual actors subject to institutionally produced normative commitments (Emirbayer and Goodwin 1994) and yet agents in the creation, reproduction, and transformation of the very institutions that shape behavior.

The difference between this approach and more conventional demographic research on social networks raises an additional question of what counts as evidence. To many demographers, this ethnographic, and largely anecdotal, account probably lacks the quantitative rigor to be convincing. Yet for many anthropologists, the quantitative counting and statistical manipulation of so many variables often begs questions of meaning and inter- 
pretation (Abbott 1992). My point is not that conventional demographic approaches to studying the influence of social networks on fertility processes are misguided, but rather that something additional can be learned by employing ethnographic methods, and taking seriously theoretical questions about the relationship between action (including network relationships) and institutions. Ethnographic evidence from Nigeria suggests that the strategic importance of kinship networks for access to resources and opportunities of the Nigerian state and economy provide a social and cultural context in which relatively high fertility remains both normatively valued and instrumentally rational.

When Igbos try to explain the strength of the obligations of kinship, even as family and community networks are stretched across vast geographical and social spaces in ways that would seem to create possibilities for greater individual latitude, they say things like 'it is our culture' or 'that is our tradition'. Even to an anthropologist, such answers beg the question: why are these kinship obligations so strong? One interesting way to think about this issue is in reference to scholarship (building on a much older tradition) on generalized exchange (Bearman 1997; Yamagishi and Cook 1993). In brief, Bearman (1997), through retrospective analysis of Australian aboriginal data, and Yamagishi and Cook (1993), through experimental data, confirm the power of systems of generalized exchange (where the giver is not compensated by the receiver, but has the expectation that his/her own needs will be fulfilled by another giver as part of a chain of exchange) in maintaining social solidarity. Bearman's and Yamagishi and Cook's arguments depend on relatively elegant data where the givers and receivers in systems of chain generalized exchange hold positions of structural equivalence. The situation is much more complex in contemporary lgboland, where givers and receivers are often vastly unequal in structural position, creating patron-clientism rather than simple reciprocal exchange. And yet the power and rationality of the system rest on principles similar to what Bearman and Yamagishi and Cook propose.

\section{Conclusion}

A widely known lgbo proverb says that a big man will have many different kinds of children. The same thing could be said about a big woman. Like many expressive proverbs, this one has multiple meanings, but foremost among them is the idea that it takes a variety of social connections provided by a diverse progeny to build and sustain high social status. Diversity is especially important in contemporary Nigeria, where lgbos depend upon 'having people' - especially relatives - placed strategically in social networks that can mobilize modern resources. The importance of diversity - and a rise of the importance of what economists call 'quality' - may be sowing the seeds for continuing fertility decline. Indeed, changing macro-sociological structures have created a situation where levels of appropriate fertility are increasingly discussed and contested. People are subject to pressures that promote both high fertility and its regulation. Still, in the current Nigerian political and eco- 
nomic context, strong ties to family, lineage, and community are the surest way to get one's share.

Ubakala - and Igboland in general is a place very much linked to the wider world. As the residents of the community and their migrant kin try to negotiate their way in contemporary Nigeria, they rely on their kinship and community networks for practical and symbolic guidance. The principles and structures of Igbo kinship organization provide people with the cultural tools to extend their families and communities across wide geographical areas and disparate cultural landscapes. To get their share of the opportunities and resources of the state and the wider Nigerian economy, Igbos rely on social relationships of patron-clientism and symbolic extensions of values of reciprocity, alliance, and obligation created by kinship. They gain access to urban resources and opportunities through their social networks of kin and association - by having people. In such a world, having big families and many children remains a rational strategy.

\section{Notes}

I. However, Igboland is generally so densely populated that there are few places that are truly remote or removed from the influence of cities and towns. Driving through lgboland, one is struck by how populated it is, how each community has its own small commercial center, and how generally developed it is compared with other parts of Nigeria, particularly the north.

2. While most Igbo communities are patrilineal, there are many excep- tions, including regions that are matrilineal (Nsugbe 1974), and others that practise double descent (Ottenberg 1968).

3. To Western eyes, a 'dash' appears to be a euphemistic way to describe a bribe. Policemen ask for dashes at checkpoints; customs officers expect it at the airport. But it can also simply be a gesture of generosity. An in-law can be given a dash after a visit, or a poor gardener might get a dash from his wealthy boss around Christmas. Most important, a dash is often a monetary symbol of some kind of personal or social relationship rather than the naked exchange of money for some (illegal or improper) action or service, as in the case with a bribe.

\section{References}

Abbott, A. 1992. "What Do Cases Do?" pp 53-82. In What is a case?, edited by $C$. Ragin and H. Becker, New York: Cambridge University Press.

Bayart, J.-F. 1993. The state in Africa: The politics of the belly. London: Longman.

Bearman, P. 1997. "Generalized Exchange." American Journal of Sociology 102:1383-14 I5

Berry, S. 1985. Fathers work for their sons: Accumulation, mobility and class formation in an extended Yoruba community. Berkeley: University of California Press.

Berry, S. 1989. "Social Institutions and Access to Resources." Africa $59(I): 41-55$.

Bledsoe, C. 2002. Contingent lives: Fertility, time, and aging in West Africa. Chicago: University of 
Chicago Press.

Brockerhoff, M. and X. Yang. 1994. "Impact of Migration on Fertility in Sub-Saharan Africa." Social Biology 4I,(I-2): 19-43.

Caldwell, J. 1982. Theory of fertility decline. London: Academic Press.

Chabal, P. and J.-P. Daloz. 1999. Africa works: Disorder as political instrument. Oxford: James Currey for the International African Institute.

Chukwuezi, B. 200I. "Through Thick and Thin: Igbo Rural-Urban Circularity, Identity and Investment." Journal of Contemporary African Studies 19,(I): 55-66.

d'Azevedo, W. 1962. "Common Principles and Variant Kinship Structures among the Gola of Western Liberia." American Anthropologist 64,(3):504-20.

Emirbayer, M. and J. Goodwin. 1994. "Network Analysis, Culture, and the Problem of Agency." American Journal of Sociology 99,(6): | 4 | |-54.

Entwisle, B., R.R. Rindfuss, D.K. Guilkey, A. Chamratrithirong, S.R. Curran, and Y. Sawangdee. 1996. "Community and Contraceptive Choice in Rural Thailand: A Case Study on Nang Rong." Demography 33,(I): I-I I.

Faist, T. and E. Ozveren, editors. 2004.

Transnational social spaces: agents, networks, and institutions. Burlington, VT: Ashgate.

Geschiere P. and J. Gugler. 1998. "The urban-rural connection: Changing issues of Belonging and Identification." Africa 68,(3):309319.

Greenhalgh, S. 1995 "Anthropology theorizes reproduction: Integrating practice, political economic and feminist perspectives" pp 3-28. In Situating fertility: anthropology and demographic inquiry, edited by $S$. Greenhalgh. Cambridge: Cambridge University Press.

Gugler, J. 2002. "The Son of a Hawk Does Not Remain Abroad: The Rural-Urban Connection in Africa." $4 I,(I): 2 I-4 I$.

Guyer, J. 1993. "Wealth in People and Self Realization in Equatorial Africa." Man 28:243-65.

Hammel, E. 1990. "A Theory of Culture for Demography." Population and Development Review 16,(3):455-85.

Howell, N. 1988. "Understanding Simple Social Structure: Kinship Units and Ties" pp 62-82. In Social structures: A network approach, edited by B. Wellman and S.D. Berkowitz. Cambridge: Cambridge University Press.

Johnson, J.C. 1994. "Anthropological Contributions to the Study of Social Networks" pp I|3-5I. In Advances in social network analysis: Research in the social and behavioral sciences, edited by S. Wasserman and J. Galaskiewicz. Thousand Oaks: Sage.

Johnson-Hanks, J. 2006. Uncertain honor: Modern motherhood in an African crisis. Chicago: University of Chicago Press.

Johnson-Hanks, J. 2007. 'What Kind of Theory for Anthropological Demography?" Demographic Research 16,(I): I-26.

Kertzer, D. and T. Fricke. 1997. "Toward an anthropological demography" pp 1-35. In Anthropological demography: Toward a new synthesis, edited by $D$. Kertzer and T. Fricke. Chicago: University of Chicago 
Press.

Kirk-Greene, A. 197I. Crisis and conflict in Nigeria. London: Oxford University Press.

Kohler, H-P., J.R. Behrman, and S.C. Watkins. 200I. The Density of Social Networks and Fertility Decisions: Evidence from South Nyanza District, Kenya. Demography 38,(I): 43-58.

Madhavan, S. A. Adams, and D. Simon. 2003. Women's Networks and the Social World of Fertility Behavior. International Family Planning Perspectives 29,(2): 58-65.

Mitchell, J.C. 1973. "Networks, Norms and Institutions" pp I5-35. In Network analysis: Studies in human interaction, edited by J. Boissevain and J.C. Mitchell. Paris: Mouton.

Mitchell, J.C. 1974. "Social Networks." Annual Review of Anthropology 3:279-99.

National Population Commission (NPC) [Nigeria] and ORC Macro. 2004. Nigeria Demographic and Health Survey 2003. Calverton, Maryland: National Population Commission and ORC Macro.

Nsugbe, P. 1974. Ohaffia: A matrilineal Igbo people. Oxford: Clarendon Press.

Ottenberg, S. 1959. "Ibo Receptivity to Change" pp 130-43. In Continuity and change in African cultures, edited by W. Bascom and R. Herzkovits. Chicago: University of Chicago Press.

Ottenberg, S. 1968. Double descent in an African society: The Afikpo village-group. American Ethnological Society Monograph Series No. 47, Seattle: University of Washington Press.
Post, K. and M. Vickers, editors. 1973. Structure and conflict in Nigeria, 1960-1966. London: Heinemann.

Rutenberg, N. and S.C. Watkins. 1997. "The Buzz Outside the Clinics: Conversations ad Contraception in Nyanza Province, Kenya." Studies in Family Planning 28,(4):290-307.

Setel, P. 1999. A plague of paradoxes: AIDS, culture and demography in northern Tanzania. Chicago: University of Chicago Press.

Silverstein, S. 1984. "Igbo Kinship and Modern Entrepreneurial Organization: The Transportation and Spare Parts Business." Studies in Third World Societies 28: 191-209.

Smith, D.J. 200I. "Kinship and Corruption in Contemporary Nigeria." Ethnos 66,(3):344-364.

Smith, D.J. 2004. "Contradictions in Nigeria's Fertility Transition: The Burdens and Benefits of Having People." Population and Development Review 30,(2):221-238.

Trager, Lilian. 200I. Yoruba hometowns: Community, identity and development in Nigeria. Boulder, CO: Lynne Rienner.

Uchendu, V. 1965. The Igbo of southeast Nigeria. Fort Worth: Holt, Reinhart and Winston.

Valente, T.W., S.C. Watkins, M.N. Jato, A. van der Stratten, and L.P. Tsitsol. 1997. "Social Network Associations with Contraceptive Use among Cameroonian Women in Voluntary Associations. Social Science and Medicine 45(5): 677-87

Watkins, S.C. and A.D. Danzi. 1995. "Women's Gossip and Social Change: Childbirth and Fertility Control among Italian and Jewish Women in the United States, 1920- 
1940." Gender and Society Networks 1:53-63.

9,(4):469-90.

Yamagashi, T, and K.S.Cook. 1993.

Whitehouse, Bruce. 2007. Exile knows no dignity: African transnational migrants and the anchoring of identity. Ph.D. dissertation in the Department of Anthropology, Brown University, Providence, Rhode Island, USA.

Wolfe, A. 1978. "The Rise of Network Thinking in Anthropology." Social "Generalized Exchange and Social Dilemmas." Social Psychology Quarterly 56,(4):235-48.

Zhang, L. 200I. strangers in the city: reconfigurations of space, power, and social networks within China's floating population. Stanford, CA: Stanford University Press 